\title{
COVID-19 Pandemic in Nigeria: misconception among individuals, impact on animal and the role of mathematical epidemiologists
}

\author{
Oluwasegun Micheal Ibrahim ${ }^{1}$ and Damilola Daniel Ekundayo ${ }^{2}$ \\ ${ }^{1}$ African Institute for Mathematical Sciences, Kigali, Rwanda \\ (oluwasegun.micheal@aims.ac.rw); \\ ${ }^{1}$ Applied Mathematics Section, Department of Mathematics, University of Benin, Benin City, Nigeria \\ (oluwasegun.ibrahim@physci.uniben.edu); \\ ${ }^{2}$ Biology Section, Department of Science Education, Abubakar Tafawa Balewa University, Bauchi, Nigeria \\ (ekundayodamilola311@gmail.com)
}

\begin{abstract}
This work considers a couple of misconceptions among Nigerian people in the COVID-19 Pandemic era. The impact of this Pandemic on animals and the role of Mathematical Epidemiologists in combatting the spread is discussed herein.
\end{abstract}

Keywords: COVID-19, Pandemic, Misconception, Mathematical Modeling, Infectious disease, Nigeria.

\section{Introduction}

The emergence of the Novel Coronavirus otherwise known as COVID-19, which broke out in the Hubei Province of China in December 2019, has no doubt hurt the socio-economic growth of the World. According to the World Health Organization (WHO), most people infected with the Novel Coronavirus will experience mild to moderate respiratory illness and recover without requiring special treatment. It is also evident that older people, and those with underlying medical problems like cardiovascular disease, diabetes, chronic respiratory disease, and cancer are more likely to develop serious illness [1]. The reward of the successful effort in containing the COVID-19 infection in Asia came about in WHO pronouncing Europe as the focal point of the illness on the 13th of March, 2020. Although the mortality rate of the Novel Coronavirus is put at 3.4\% by the WHO as of the 3rd of March, 2020 [2], the rate at which it spreads is alarming. Currently, COVID-19 is said to have affected all the Continents of the World with Europe being one of the hardest-hit continents. According to Our World in Data (OWD) report on the 4th of April, 2020, Italy sits comfortably at the top of the chart of the death rate with more than 15,000 deaths recorded and many others infected while the United States of America (USA) is currently the highest hit with more than 50,000 deaths recorded as at the 26th of April, 2020 [3]. Many nations of the world are currently experiencing partial lockdown while, others are experiencing a total lockdown. In this regard, we discuss briefly a few misconceptions circulating around and as well report the recent manifestation of the transmission of the disease from humans to animals. We also highlight the roles Mathematical Epidemiologists could play in reducing the spread of the Pandemic and make recommendations for policymakers. 


\section{Misconception and Impact on Human}

As the medical experts and scientists in the world work tirelessly towards finding COVID-19 vaccines, it is worthy of note that the Pandemic virus is still surrounded by a lot of misconceptions in Africa. The WHO says the disease has sparked an "infodemic". This implies that a staggering amount of information on social media, some simply false. In particular, some people in Nigeria believe that the COVID-19 is not real; others indeed believe that it is real but cannot affect the poor or those who don't travel beyond the country. Another school of thought believed that some sorts of alcoholic substances and concoction could cure the virus or prevent them from getting infected.

A good number of people believe that it is a "richman's virus" and so it can not affect the poor masses. Others believe that COVID-19 cannot survive in a region around the equator as the temperature would kill it. However, with more than 1,273 people infected and 40 deaths recorded already in Nigeria as indicated on Nigeria Centre for Disease Control (NCDC) website [4] and 31,933 people infected and 1,423 deaths recorded across Africa as indicated on Africa Centre for Disease Control (ACDC) website [5], it is crystal clear that the virus is not selective as it keeps infecting the rich and the poor alike and could potentially spread on African soil if not combated since the figures are becoming more frightening daily.

The false claims that the virus could be cured or prevented by drinking the alcoholic substance, eating of garlic, lemon, and good food to strengthen body immune system and the likes, have been debunked by the WHO and many medical experts around the world. The only way out of it at the moment is premised on personal hygiene - which includes regular hand washing, social distancing, avoidance of large gathering, and regular decontamination of the environment, etc. A lot of media files (most often video, audios) have been circulating on social media with the claim that some drugs combination can potentially reduce symptoms, unfortunately, there are no data or known research conducted by the authors of this information to back up their recommendations. An illiterate or literate that cannot source for a fact will hook-line-andsink such an idea and drug abuse becomes the order of the day. A strict measure was recently introduced by a popular social media platform "Whatsapp" with more than 2 billion people in over 180 countries across the world to limit viral message forwards to one chat at a time in order to stem the rapid spread of COVID19 misinformation [6]. Although a user could theoretically still forward the same message to individuals or group one by one but it is believed this limitation will be effective in preventing a spread of untrue information about the Pandemic.

While some countries such as the USA, among others are experimenting with the use of Chloroquine for some patients, clinical trials are still ongoing in some other countries for possible vaccines that will be globally acceptable. A recent study conducted in Italy suggests that it is hard to find a product right now that has a superior safety profile than Chloroquine [7]. Besides, its expense is minimal and could be affordable by all. Thus, its possible use both in Prophylaxis in people exposed to the Novel Coronavirus and as a curative treatment will probably be promptly evaluated by our Chinese colleagues. If clinical data confirm the biological results, the COVID-19-associated disease will have become one of the simplest and cheapest to treat and prevent the infectious respiratory diseases [7]. African scientists, in particular, Nigeria should intensify effort in conducting clinical research that could help battle the Pandemic. 


\section{Impact on Animal}

According to the World Organization for Animal Health (formerly known as International des Epizooties (OEI) [8], there is no evidence that dogs or cats are playing a vital role in the spread of COVID-19. However, the infected humans or pet owners should be aware that they can potentially transmit this disease to their pets, hence, it is quite instructive to keep animals separated from any person who has COVID-19 symptoms. On the 5th of April, 2020, the United States Department of Agriculture (USDA) has confirmed SARS-CoV-2 (the virus that causes COVID-19 in humans) in one Tiger at a zoo in New York [9]. As stated in the USDA report, this is the first instance of a Tiger being infected with COVID-19 as several lions and tigers at the zoo showed symptoms of respiratory illness. It is believed that the Tiger became sick after possible exposure to a zoo employee who was actively shedding the virus [9].

It is important to note that there is no strong evidence to suggest that many animals, including pets or livestock, can spread COVID-19 infection to people, however, individuals sick with COVID-19 or showing symptoms of COVID-19 should restrict contact with pets and other animals, just like you would with other humans. As indicated in the CDC report [10], there have not been reports of pets becoming sick with COVID-19 in the United States, it is still recommended that people sick with COVID-19 limit contact with animals until more information is known about the virus. When possible, have another member of your household care for your animals while you are sick. It was further stressed that there is no evidence to suggest that imported animals or animal products pose a risk for spreading COVID-19 in the USA. This is a rapidly evolving situation and information will be updated as it becomes available [10]. We do feel Africa, Nigeria in particular, can take a clue from this recommendation. The news that a Tiger tested positive to COVID-19 in a Zoo somewhere in the USA portends great danger to the people and economy of Nigeria. This is because a great number of a section of Nigerians in the Northern part of the country are nomadic livestock farmers, who travel around the nation always. If any of their animals contract COVID-19, the negative impact of such is only best imagined as it is capable of wreaking further havoc on the already battered economy of the nation and the wellbeing of the citizens. In a moment like this, individual diagnose with COVID-19 disease should avoid unnecessary contact with animals, in particular, pets. Ultimately, regularly hand washing before and after interacting with animals is essential.

\section{Role of Mathematical Epidemiologist}

The study in [11] considers a comparison between the number of confirmed cases in the worst affected European countries and the West African countries with confirmed COVID-19 cases. Based on the research, it was evident that the virus can as well spread in countries with warmer climates. On account of West Africa, a fast quickening in the number of cases could rapidly overpower the vulnerable health system such as public or private health Institutions. Swift action to control further spread of the infection, and to improve the response capacities of affected nations in West Africa is, therefore, urgent [11].

Mathematical Modeling, in particular, infectious disease modeling serves as an indisputable tool that could be used to further understand the dynamics of COVID-19 pandemic in Africa and beyond. One way to do this is by constructing deterministic models that could help in gaining both qualitative and quantitative 
insight into the dynamics of the Novel Coronavirus. For further readings on mathematical modeling of infectious disease, see the excellent work in Huppert and Katriel (2013) [12]. The susceptible exposed infected and recovered (SEIR) framework could be employed. According to WHO it takes a maximum of 14 days before the symptoms can manifest in infected individuals [13]. As a result, the exposed class gives detailed information about individuals in the latent stage (when the symptoms have not manifested in the infected individuals but they are capable of infecting susceptible individuals) within the 14 days incubation period.

From the infectious disease modeling perspective, one should be concerned about the basic reproduction $\left(R_{0}\right)$ of the disease in humans. The $R_{0}$ is the number of secondary infections generated from one infected individual, this is understood to be between 2 and 2.5 for the COVID-19 [13]. Mathematically formulating the $R_{0}$, the progression of the disease could be monitored over time. See Okuonghae and Omosigho (2011) [14] for extensive analysis of an SEIR model with effective use of the $R_{0}$ to combating a respiratory-like disease from a population. Another interesting tool to watch out for is the force of infection which can be modeled mathematically and measured with the relevant data. Since it is not well established that animals can transmit this disease, it is however not certain whether a $R_{0}$ can be obtained for the animal population at the moment, but it could be possible if there is an increase in infection among animals of similar and non-similar species.

Another interesting aspect of mathematical epidemiology is the application of optimal control in resourcepoor/limited settings. Most African countries (including Nigeria being the country with the largest economy in Africa) cannot fight this Pandemic without intervention funds or health support from the Western World. This intervention may not be sufficient for the entire population, hence, there is a need for proper maximization of the available resources while minimizing cost. More importantly, this approach is needful when there is insufficient or no commitment from the funding body. Furthermore, employing tools from dynamical system theory could help us determine parameters that are sensitive to the situation at hand. We are hopeful that the ongoing research on the disease vaccine becomes successful; Mathematical Modeling could help policymakers to determine the proportion of the population to be vaccinated and also check for vaccine wane rate and its effect. The current Pandemic in Nigeria, should not be seen as the work of those in Public Health or Biomedical Sciences, instead, experts in other areas such as Applied Mathematics, Statistics, and a lot more can be encouraged to join the response team to tackling the deadly disease. If the government can invest in research, scientists at various levels and fields could team up and come up with a long-lasting solution that can potentially eradicate the Pandemic.

\section{Conclusion}

As the World, especially Nigeria, struggles to contain the spread of COVID-19, the need for personal hygiene, social distancing, regular hand washing, avoidance of large gatherings and other preventive/precautionary measures cannot be over-emphasized. By not letting out our guard now, we can save ourselves and others from contracting the virus and as well contain its spread among human beings. More than never before, the government at various levels and media houses must intensify public enlightenment to clarify the misconceptions that many still have about the Novel Coronavirus. While there is no vaccine for COVID-19 at the moment, testing, staying home and staying safe remain our best arsenal. 


\section{References}

[1.] WHO, 2020. Healthtopics:Coronavirus, https://www.who.int/healthtopics/coronavirus\#tab=tab_1, accessed: 10-04-2020.

[2.] WHO, 2020. Director-General's opening remarks at the media briefing on COVID-19. World Health Organization, March 3, 2020, https://www.who.int/dg/speeches/detail/who-director-general-s-openingremarks-at-the-media-briefing-on-covid-19---3-march-2020, accessed: 06-04-2020.

[3.] OWD, 2020 https://ourworldindata.org/coronavirus\#the-growth-rate-of-covid-19-deaths, accessed: 27-042020.

[4.] NCDC, 2020. https://covid19.ncdc.gov.ng, accessed: 27-04-2020.

[5.] ACDC, 2020. https://africacdc.org/covid-19, accessed: 27-04-2020.

[6.] CNBC News, 2020. https://www.cnbc.com/2020/04/07/whatsapp-limits-message-forwards-to-combatcoronavirus-misinformation.html, accessed: 08-04-2020.

[7.] Colson, P., Rolain, J. M. and Raoult, D., 2020. Chloroquine for the 2019 Novel Coronavirus SARS-CoV-2, International Journal of Antimicrobial Agents, $\quad 55(3)$ : $1-2$, doi: https://doi.org/10.1016/j.ijantimicag.2020.105923.

[8.] OIE, 2020. https://www.oie.int/en/scientific-expertise/specific-information-andrecommendations/questions-and-answers-on-2019novel-coronavirus, accessed: 06-04-2020.

[9.] USDA, 2020. https://www.aphis.usda.gov/aphis/newsroom/news/sa_by_date/sa-2020/ny-zoo-covid-19, accessed: 06-04-2020.

[10.] CDC, 2020. https://www.cdc.gov/coronavirus/2019-ncov/daily-life-coping/animals.html, accessed: 06-04-2020.

[11.] Martinez-Alvarez, M., Jarde, A., Usuf, E., Brotherton, H., Bittaye, M., Samateh, A. L., Antonio, M., Vives-Tomas, J., D'Alessandro, U. and Roca, A., 2020. COVID-19 Pandemic in West Africa. The Lancet Global Health, 1-2, doi: https://doi.org/10.1016/S2214-109X(20)30123-6.

[12.] Huppert, A. and Katriel, G., 2013. Mathematical modelling and prediction in infectious disease epidemiology. Clinical microbiology and infection, 19(11): 999-1005.

[13.] WHO, 2020. Coronavirus Disease 2019 (COVID-19) Situation Report - 46, March 6th, 2020, https://www.who.int/docs/default-source/coronaviruse/situation-reports/20200306-sitrep-46-covid-19.pdf, accessed: 07-04-2020.

[14.] Okuonghae, D. and Omosigho, S. E., 2011. Analysis of a mathematical model for tuberculosis: What could be done to increase case detection. Journal of theoretical biology, 269(1): 31-45, doi: https://doi.org/10.1016/j.jtbi.2010.09.044. 